\title{
TUANNY PRISCILA SCHMIDT
}

\section{AVALIAÇÃO FARMACOLÓGICA DE UMA NANODISPERSÃO CONTENDO GYY4137 (DOADOR DE LIBERAÇÃO LENTA DE $\mathrm{H}_{2} \mathrm{~S}$ ) NA PSORÍASE EXPERIMENTAL}

Dissertação apresentada ao Programa de Pós-Graduação em Farmacologia do Instituto de Ciências Biomédicas da Universidade de São Paulo, para obtenção do Título de Mestre em Ciências.

Área de concentração: Farmacologia

Orientadora: Profa. Dra. Soraia K. P. Costa

Versão corrigida. A versão original eletrônica encontra-se disponível tanto na Biblioteca do ICB quanto na Biblioteca Digital de Teses e Dissertações da USP (BDTD)

São Paulo

2015 


\section{RESUMO}

Schmidt TP. Avaliação farmacológica de uma nanodispersão contendo GYY4137 (doador de liberação lenta de $\mathrm{H}_{2} \mathrm{~S}$ ) na psoríase experimental. [Dissertação (Mestrado em Farmacologia)] - São Paulo: Instituto de Ciências Biomédicas, Universidade de São Paulo; 2015

A psoríase é uma doença inflamatória crônica, imunomediada, de alta incidência, cujas lesões de pele e prurido intenso, reduzem a qualidade de vida dos pacientes. Previamente, o grupo demonstrou que o tratamento sistêmico com o doador de sulfeto de hidrogênio $\left(\mathrm{H}_{2} \mathrm{~S}\right)$ de liberação lenta (GYY4137) inibiu significativamente a inflamação cutânea e o prurido em modelo de psoríase induzido por imiquimode (IMQ). A fim de aprofundar esse conhecimento, os objetivos deste estudo foram: i) desenvolver e caracterizar formulações tópicas $(4$ microemulsões e 1 nanodispersão), como veículo do GYY4137; ii) avaliar o efeito terapêutico da formulação selecionada sobre o prurido, inflamação e Índice de Severidade e Área da Psoríase (PASI) em camundongos Balb/c, iii) avaliar possíveis diferenças na geração de $\mathrm{H}_{2} \mathrm{~S}$ na pele de animais com psoríase e iv) averiguar comparativamente o efeito farmacológico e toxicológico do composto em estudo (GYY4137) em relação à mesma formulação contendo dexametasona. Dentre as formulações desenvolvidas, a nanodispersão mostrou-se menos irritante, visto que nem inflamação cutânea e tampouco prurido foram observados nos animais, diferentemente das demais preparações. A aplicação tópica diária do IMQ creme (5\%; $65 \mathrm{mg}$; Germed, Brasil) na pele dorsal depilada e superfície da orelha dos camundongos, durante cinco dias consecutivos, promoveu prurido bem como sinais (PASI) compatíveis com a psoríase vulgar, em relação ao controle que recebeu o veículo (vaselina). Animais controle ou com psoríase foram tratados, uma ou duas vezes/dia, com a nanodispersão (65 mg) contendo GYY4137, dexametasona ou apenas veículo. O PASI, e o prurido foram mensurados diariamente, enquanto a concentração de citocinas inflamatórias (IL-6 e IL-1ß), leucócitos periférico, esplenócitos, esplenomegalia, atividade da mieloperoxidase (MPO) e outros marcadores de inflamação, foram quantificados no ultimo (6ํ) dia. Em relação à terapia com uma ou duas doses diária da nanodispersão contendo GYY4137 4\%, observou-se que a aplicação duas vezes/dia mostrou-se $(P<0.05)$ mais eficaz na redução dos parâmetros inflamatórios e PASI, mas reduziu, de forma não significativa, o prurido. Foi observado uma redução na geração de $\mathrm{H}_{2} \mathrm{~S}$ na pele dos animais com psoríase, a qual foi parcialmente revertida pelo tratamento com GYY4137 (4\%), 2x/dia. Sobre a formulação contendo dexametasona (4\%), nota-se que os efeitos farmacológicos foram estatisticamente semelhantes àqueles obtidos com GYY4137 (4\%), contudo o doador de $\mathrm{H}_{2} \mathrm{~S}$ se mostrou mais seguro, pois nem efeitos sistêmicos e tampouco toxicológicos significativos foram observados. Conclui-se que a terapia com a nanodispersão contendo 4\% de GYY4137 possui potencial terapêutico seguro para reduzir sinais e sintomas associados à psoríase.

Palavras-chave: Psoríase. Imiquimode. Sulfeto de Hidrogênio. GYY4137. Dexametasona. Nanodispersão. 


\begin{abstract}
Schmidt TP. Pharmacological evaluation of a nanodispersion system containing an slow release donor of $\mathrm{H}_{2} \mathrm{~S}$ (GYY4137) in an experimental model of psoriasis. [Master thesis (Pharmacology) ] - São Paulo: Instituto de Ciências Biomédicas, Universidade de São Paulo; 2015

Psoriasis is a chronic inflammatory disease, immune-mediated, with a high world incidence, whose skin lesions and intense itching, reduce markedly the life quality of patients. Previously, the group has shown that systemic treatment with the slow release donor of hydrogen sulfide $\left(\mathrm{H}_{2} \mathrm{~S}\right)$, GYY4137, significantly inhibited skin inflammation and itching in a experimental model of psoriasis induced by imiquimod (IMQ). In order to further this knowledge, the aims of this study were: i) to develop and characterize topical formulations (four microemulsion and one nanodispersion), as a vehicle for GYY4137; ii) to evaluate the therapeutic effect of the selected formulation on the itching behaviour, inflammation and Psoriasis Area Severity Index (PASI) in mice BALB/c iii) to evaluate differences in $\mathrm{H}_{2} \mathrm{~S}$ generation in animal skin with psoriasis and iv) ascertain comparatively the pharmacological effect and toxicological potential of the selected formulation containing 4\% GYY4137 in relation to the same formulation containing dexamethasone. Amongst the developed formulation, the nanodispersion proved to be less irritating in murine skin, since neither inflammation nor skin rash was observed in animals, unlike the other four preparations. The daily topical application of IMQ cream (5\%; 65 mg; Germed, Brazil) in the mice shaved dorsal skin and ear surface, for five consecutive days, promoted itching as well as signs and symptoms consistent with the signs and symptoms of psoriasis (PASI) compared to the control group, which received the vehicle (Vaseline). Control or animals with psoriasis were treated daily once or twice with a nanodispersion (65 mg) containing GYY4137, dexamethasone or vehicle. PASI and pruritus were measured daily while the concentration of inflammatory cytokines (IL-6 and IL-1 1 ), peripheral leukocytes, spleen, splenomegaly, myeloperoxidase activity (MPO) and other inflammatory markers were measured on the last $\left(6^{\text {th }}\right)$ day. The therapy with one or two daily doses of nanodispersion containing 4\% GYY4137 showed that two daily doses showed to be $(P<0.05)$ more effective in reducing the inflammatory parameters and PASI, but only reduced, in a not significant manner, the itching behaviour. Animal with psoriasis also showed a reduction in $\mathrm{H}_{2} \mathrm{~S}$ skin generation, wich was partially reversed by GYY4137 (4\%, 2x/day) treatment. Regarding the formulation containing dexamethasone, it should be noted that the pharmacological effects were statistically similar to those obtained with $4 \%$ GYY4137, except that the effects produced by the latter was safer since neither systemic effects nor toxicological potential were observed. In conclusion, the treatment with the nanodispersion containing 4\% GYY4137 exhibited safer therapeutic potential for reducing signs and symptoms associated with psoriasis.
\end{abstract}

Key words: Psoriasis. Imiquimod. Hydrogen Sulfide. GYY4137. Dexamethasone. Nanodispersion. 


\section{INTRODUÇÃO}

\subsection{Qualificação do principal problema abordado: Psoríase}

A pele é o maior órgão do corpo humano, abrangendo uma área de até dois $\mathrm{m}^{2}$ e constitui cerca de $16 \%$ do peso corporal em indivíduos adultos. É um órgão sensorial que atua como uma barreira ativa entre o organismo e o ambiente, a qual impede a penetração de agentes externos (ex.: microrganismos e radiação ultravioleta), auxilia na regulação da temperatura corporal e protege o organismo contra lesões mecânicas e térmicas (Barry, 1983; Shai et al., 2009). Estruturalmente, é subdividida em duas partes principais: epiderme e derme. A epiderme consiste na camada mais externa e é composta por epitélio estratificado escamoso queratinizado, constituído em $90 \%$ por queratinócitos, $8 \%$ por melanócitos e o restante por células de Langerhans e de Merkel. Já a derme, camada mais profunda, é composta principalmente por tecido conjuntivo contendo fibras colágenas e elásticas (Mcglone, Reilly, 2010; Tortora, Grabowski, 2006).

Trata-se de um órgão extremamente inervado, cujas fibras aferentes sensoriais especializadas e eferentes autonômicas inervam glândulas sebáceas, sudoríparas, vasos sanguíneos e folículos capilares. Nela encontramos uma vasta rede imunológica formada por células apresentadoras de antígenos, células T e mastócitos (Mcglone, Reilly, 2010). Várias doenças dermatológicas como por exemplo a psoríase e a dermatite atópica, ocorrem devido a alterações na homeostasia da pele, afetando a interação entre as células imunes, nervosas e os queratinócitos (Di Meglio et al., 2011).

A psoríase é uma doença inflamatória crônica, imunomediada, não contagiosa, que se manifesta na pele e/ou articulações de 2 a $4 \%$ da população mundial (Mrowietz et al., 2011; Parisi et al., 2013). No Brasil a prevalência dessa doença não está ainda bem estabelecida, mas sugere-se que ela afeta, pelo menos, 1\% da população (Sociedade Brasileira de Dermatologia - SBD, 2014).

A forma mais comum da doença é conhecida como psoríase vulgar, caracterizada por placas avermelhadas, escamosas, bem delimitadas e de tamanho variável, que podem se manifestar principalmente nos joelhos, cotovelos, região prétibial, couro cabeludo e região sacral, ou, envolver quase toda a superfície corporal (Krueger, Bowcock, 2005; SBD, 2014; Parisi et al., 2013). No entanto, existem outras 
formas clínicas de psoríase, tais como: invertida, em gotas, eitrodérmica, pustulosa e seboríase. Dependendo da gravidade, a psoríase pode acometer as articulações, originando a artrite psoriática, que afeta 5 a $40 \%$ dos pacientes (Furst, 2011; SBD, 2014).

Apesar do pouco conhecimento da etiologia da psoríase, sabe-se que ela possui características multifatoriais, podendo ser deflagrada por fatores genéticos e ambientais, como traumas, agentes farmacológicos, estresse, fumo, infecções, obesidade e consumo de álcool (Krueger, Bowcock, 2005; Mabuchi et al., 2012; Naldi, 2013). A incidência dessa doença é mais comum entre parentes de primeiro e segundo grau, do que em outros indivíduos da população em geral. Ainda, entre gêmeos monozigóticos a incidência da psoríase é, pelo menos, 2 a 3 vezes maior do que entre gêmeos heterozigóticos (Nestle et al., 2009).

Estudos de genoma identificaram nove loci cromossômicos relacionados à psoríase, denominados "PSORS" de 1 a 9 (genes de susceptibilidade à psoríase). Em torno de 35 a $50 \%$ da hereditariedade da psoríase está relacionada ao gene PSORS 1, considerado o fator genético determinante da doença (Bos et al., 2005; Nestle et al., 2009).

A idade, etnia e localização geográfica são também outros fatores importantes que contribuem para a prevalência da psoríase. Por exemplo, as crianças são menos acometidas pela psoríase do que os indivíduos adultos. Em países localizados próximos a linha do Equador (Egito, Tanzânia, Sri Lanka e Taiwan), a incidência da psoríase é menor do que na Europa e Austrália (Naldi, 2013; Langley et al., 2005; Parisi et al., 2013).

Em relação a fisiopatologia, acredita-se que espessamento das lesões ocorre devido a uma série de alterações na epiderme, como hiperplasia de queratinócitos, paraceratose e infiltrado celular, resultante da angiogênese e acúmulo de células inflamatórias na derme, envolvendo grande população de células apresentadoras de antígeno (ex.: células dentríticas (CDs) e macrófagos) e células $\mathrm{T}$, um dos principais alvos nas lesões psoriásicas (Naldi, 2013; Nestle et al., 2009). Na figura 1 é possível observar as alterações estruturais na pele psoriásica, quando comparada a uma pele saudável. 
Figura 1 - Diferenças entre pele saudável e pele com psoríase.

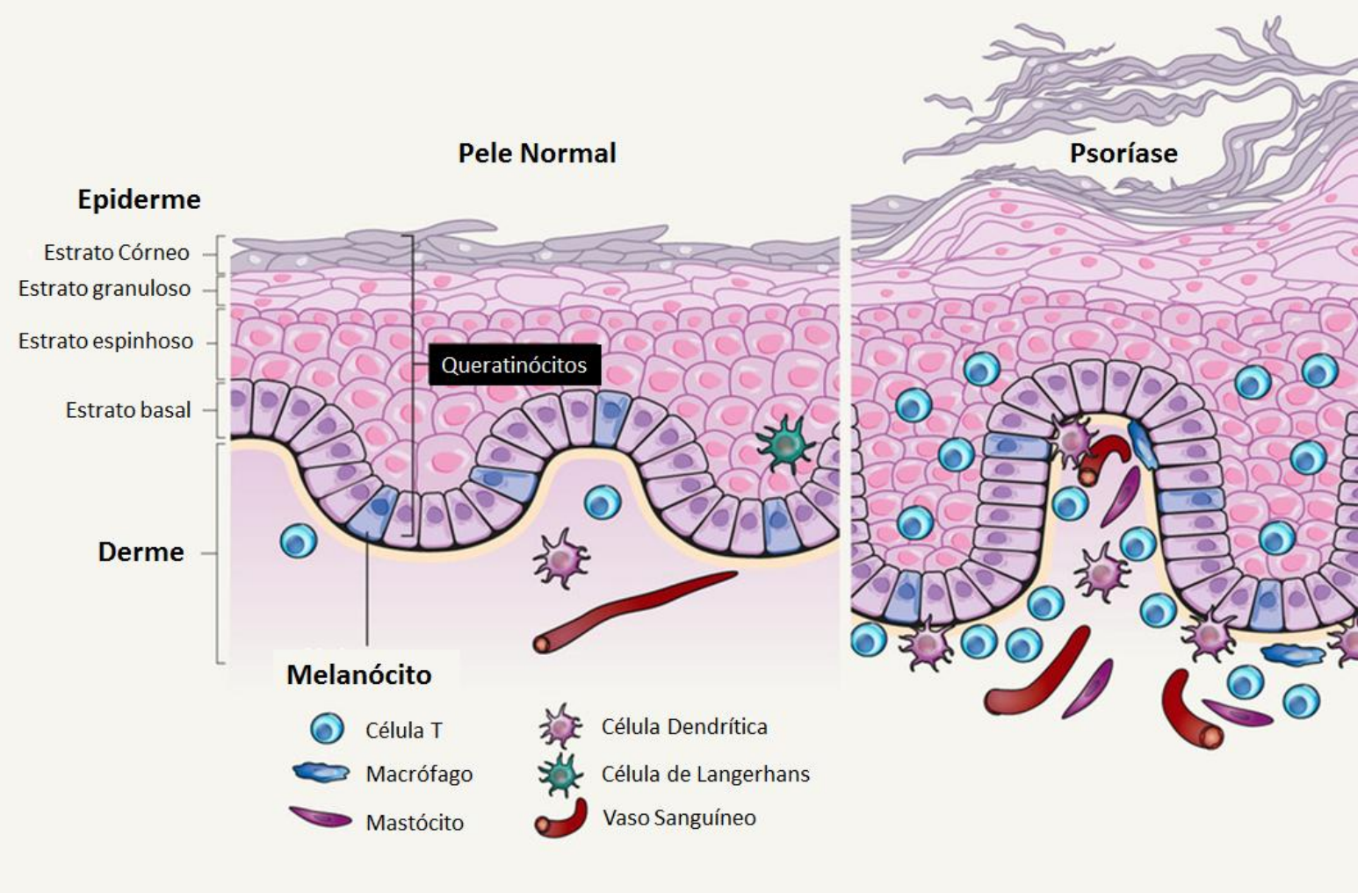

Fonte: Crow, 2012.

Quando ativadas, as CDs migram para o linfonodo regional, onde apresentam antígenos para os linfócitos T (LT) que, por sua vez, são ativados e diferenciam-se em células T helper (auxiliares) 1 e 2 (Th1 e Th2). As células Th1 produzem e liberam várias citocinas e quimiocinas inflamatórias, incluindo o intérferon $\gamma$ (INF $\gamma$ ) fator de necrose tumoral a (TNFa) e IL-2. Além disto, estimulam a diferenciação das células T helper 17 (Th17) que, subsequentemente, geram mais citocinas: IL17, IL-6, IL-22 e o TNFa. As células Th diferenciadas migram para a derme, onde interagem com as células apresentadoras de antígenos (CDs, macrófagos) que, por sua vez, produzem outros tipos de citocinas (ex.: IL-12 e IL-23). Estas, por seu turno, facilitam a proliferação de linfócitos Th1/Th17 responsáveis pela manutenção da inflamação cutânea psoriásica (Bos et al., 2005; Lima, Lima, 2011; Nestle et al., 2009).

A complexa imunopatogênese da psoríase engloba tanto a desregulação do sistema imune inato - SII (queratinócitos, CDs, macrófagos, mastócitos, neutrófilos e células endoteliais), quanto imune adquirido - SIA (LT) (Bos et al., 2005; Nestle et al., 2009; Sanchez, 2010). Muito embora os fatores ambientais representam alguns dos principais mecanismos de ativação das células do SII (ex.: queratinócitos, CDs), 
com consequente desencadeamento da cascata inflamatória, a ativação de receptores do tipo toll like (TLR) por ligação com antígenos infecciosos parece atuar como um mecanismo alternativo no desencadeamento ou fisiopatologia da psoríase (Nestle et al., 2009).

Nesse sentido, a indução da psoríase experimental resultante da aplicação tópica do fármaco agonista de receptores TLR7 e TLR8, denominado imiquimode (IMQ), e terapeuticamente indicado para o tratamento do vírus papiloma humano (HPV), tem sido demonstrada em recentes estudos que empregam camundongos. Estes revelaram alguns dos sinais e sintomas bem característicos (PASI) da psoríase humana (Flutter, Nestle, 2013; Shibata et al., 2013; van der Fits et al., 2009; Yanaba et al., 2013). É interessante ressaltar que o emprego do fármaco IMQ em indivíduos com psoríase exacerbou o grau de severidade (PASI) da doença, bem como deflagrou-a em usuários sem essa enfermidade (van der Fits et al., 2009).

O presente modelo de psoríase experimental induzido por IMQ vem sendo amplamente empregado, desde a sua primeira utilização, em 2009, principalmente pela sua capacidade de manifestar, não somente os sinais clínicos (lesões de pele espessas, descamativas e avermelhadas) relacionados a psoríase, mas também alterações imunológicas, como proliferação epidérmica, diferenciação anormal e acúmulo de neutrófilos, células dendriticas e plasmócitos na derme, bem como maior expressão epidérmica das interleucinas IL-17, IL-23, IL-6 e IL-1ß (Flutter, Nestle, 2013; van der Fits et al., 2009). Ademais, outra grande vantagem do modelo, é o seu baixo custo, facilidade e rapidez de execução, quando comparado aos demais modelos disponíveis, como àqueles que utilizam xenotransplante e mutações espontâneas (Schon, 2008; van der Fits et al., 2009).

O prurido intenso é um dos principais sintomas relatados por pacientes com psoríase vulgar (Gupta et al., 1988; Newbold, 1977; Szepietowski et al., 2002; Yosipovitch et al., 2000). O prurido ou coceira, do latim pruritus, pode ser definido como uma percepção incômoda na pele, capaz de desencadear a necessidade de se coçar (Wahlgren, 1995), ainda conhecido popularmente como comichão. Assim como a dor, o prurido serve como um mecanismo de autoproteção, pois ajuda a preservar o corpo de danos causados por agentes externos lesivos/irritantes, que tenham ultrapassado a barreira epidérmica e penetrado na pele. Pode ser também resultante de alterações sistêmicas relacionadas ao descontrole de doenças, como diabetes (Ikoma et al., 2005). 
Dentre os principais mediadores pruritogênicos envolvidos na deflagração do prurido agudo cutâneo, a histamina é bastante conhecida; todavia, esse mediador não parece ter grande relevância na indução do prurido crônico relacionado à psoríase em humano (Reich, Szepietowski, 2007). Por outro lado, mediadores endógenos, tais como, os neuropeptídios substância $\mathrm{P}(\mathrm{SP})$, peptídeo da calcitonina relacionado ao gene (CGRP), polipetídeo vasoativo intestinal e o neuropeptídeo $Y$ estão intimamente relacionados no prurido crônico observado na psoríase (Amatya at al., 2011; Reich, Szepietowski, 2007). Mais recentemente, sugeriu-se que o aumento da concentração de IL-31 está associado ao grau de intensidade do prurido na psoríase (Gangemmi et al., 2013; Narbutt et al., 2013).

A IL-31 pertence a família da IL-6 (Gangemmi et al., 2013; Zhang et al., 2008), cuja geração é regulada por células CD4+ Th2 ativadas. Interage com o receptor heterodimérico, subdividido em receptores da IL-31 (IL-31R) e $\mathrm{M}$ da oncostatina (OSMR) (Sonkoly et al., 2006; Zhang et al., 2008). O subtipo IL-31R está expresso constitutivamente na pele, próstata, testículos, ovários, placenta, cérebro, pulmão, traqueia, musculo esquelético, baço e medula óssea de humano e rato (Zhang et al., 2008). Já a expressão do receptor OSMR funcional para IL-31 foi demonstrada em neurônios nociceptivos dos gânglios da raiz dorsal (GRD), que se projetam para a pele (Zhang et al., 2008), reforçando assim a sugestão de que 0 prurido em pacientes com psoríase é modulado pela IL-31 (Sonkoly et al., 2006). De fato, níveis séricos elevados de IL-31 estão correlacionados ao desejo de coçar-se em pacientes com psoríase e outras dermatites, como a dermatite atópica (DA), de contato (DAC) e mastocitose, (Gangemmi et al., 2013; Narbutt et al., 2013; Neis et al., 2006; Nobbe et al., 2012; Rabenhorst, Hartmann, 2014; Sonkoly et al., 2006; Takaoka et al., 2006; Zhang et al., 2008).

Vale acrescentar que os gânglios da raiz dorsal, assim como os macrófagos, eosinófilos, basófilos e queratinócitos ativados, expressam receptores para IL-31 (IL31R + OSMR) (Rabenhorst, Hartmann, 2014; Sonkoly et al., 2006). Cevikbas et al. (2014) revelaram que a ausência/deleção de receptores de potencial transiente vaniloide (TRPV1) ou anquirina (TRPA1) reduz grandemente o prurido induzido pela administração i.d. de IL-31 em pele de camundongos. Isto sugere o envolvimento desses receptores no mecanismo pruriceptivo mediado pela IL-31. 


\subsection{Psoríase e tratamentos farmacológicos}

A terapia farmacológica para a psoríase vulgar varia de acordo com as manifestações clínicas e o grau de severidade e extensão da doença (SBD, 2014). Para os casos leves e moderados, preconiza-se o emprego de terapias medicamentosas, como a corticoterapia tópica, análogos da vitamina $\mathrm{D}$, ditranol e o retinóide tazaroteno. Nas formas mais severas da doença, recomenda-se a terapia sistêmica com agentes imunossupressores e quimioterápicos (ex: ciclosporina, metotrexato e retinóides) associada à terapia tópica e fototerapia (Beyer, Wolverton, 2010; Schön, Boehncke, 2005).

Muito embora o tratamento tópico com corticosteroides seja bem estabelecido e com menor probabilidade de induzir efeitos adversos, alguns estudos mostram que a aplicação tópica prolongada de corticoides potentes em área extensa da pele de pacientes com psoríase, resulta em absorção sistêmica desse fármaco, capaz de causar não somente supressão adrenal, mas também promover rápida indução de hipercortisolismo (Síndrome de Cushing) (Castela et al., 2012; Garden, Freinkel, 1986). Assim, a introdução de novos fármacos de ação tópica isentos das ações adversas dos corticosteroides ainda se faz necessária.

Apesar do atual conhecimento dos agentes biológicos (ex.: adalimumabe, infliximabe e ustekinumabe) como principais alvos de tratamentos para os casos moderados e graves da psoríase, essa classe farmacológica apresenta desvantagens, como a inconveniência de administração sistêmica, ocorrência de efeitos adversos paradoxais e aumento da susceptibilidade a infecções graves, tal como a tuberculose (Kroesen et al., 2003, Mathur et al., 2011; Singh et al., 2011). Somado a isto, o custo elevado dessa classe de fármacos constitui outro fator limitante de adesão ao tratamento, particularmente nos países em desenvolvimento (Chi, Wang, 2014; Diamantino, Ferreira, 2012).

Muito embora a indicação farmacológica dos agentes anti-histamínicos $\mathrm{H} 1$ no alivio do prurido agudo é bem conhecida, o envolvimento dos receptores histaminérgicos e da histamina não parece ser relevante na psoríase e tampouco no prurido crônico relacionado. Somente $20 \%$ dos pacientes com psoríase relatam melhora do sintoma de prurido com a terapia oral com anti-H1 (Reich, Szepietowski, 2007). Até o presente momento, nenhum relato na literatura demonstra qualquer relação entre a intensidade do prurido e concentrações de histamina no plasma de 
pacientes com psoríase (Reich, Szepietowski, 2007; Yosipovitch, Bernhard, 2013). Da mesma forma, não foram detectadas diferenças significativas nos conteúdos séricos de histamina de pacientes com psoríase pruriginosa em relação àqueles com a forma não pruriginosa. Isto explica, em parte, a baixa eficácia terapêutica antiprurido dos anti-H1 em pacientes com psoríase (Reich, Szepietowski, 2007; Yosipovitch, Bernhard, 2013).

Considerando-se que a terapia atual não supre efetivamente ou parcialmente às necessidades do controle dos sinais e sintomas da psoríase vulgar, associado ao fato que a terapia mais promissora com agentes biológicos apresenta 0 inconveniente do alto custo, baixa adesão e, principalmente, efeitos adversos graves, acredita-se ser pertinente a contínua busca por terapias alternativas ou complementares para o tratamento da psoríase e os sintomas relacionados, principalmente o prurido crônico, que afeta grandemente a qualidade de vida dos indivíduos acometidos.

Acredita-se que os pacientes com psoríase vulgar tendem a se beneficiar com as novas terapias tópicas, uma vez que essas apresentam melhor comodidade para aplicação, exclusão do metabolismo hepático do fármaco e, consequentemente, menos efeitos colaterais (Kreilgaard, 2002; Williams, 2012). Por conseguinte, novas estratégias terapêuticas associadas aos novos sistemas de entrega tópica de fármacos, parecem ser ideais e necessários para os tratamentos de longa duração dos eventos inflamatórios de doenças crônicas, como a psoríase. Nesse sentido, evidências farmacológicas mostram um papel promissor para $0 \mathrm{H}_{2} \mathrm{~S}$, $\mathrm{O}$ novo mediador gasoso ( $\mathrm{Li}$ et al., 2011; Lowicka, Bettowski, 2007) no controle de processos inflamatórios e nociceptivos (Chen et al., 2009; Cunha et al., 2008; Ekundi-Valentim et al., 2010, 2013; Wang, 2012; Whiteman et al., 2010; Zanardo at al., 2006).

\subsection{Sulfeto de hidrogênio e controle das respostas inflamatória e sensorial}

A síntese endógena do $\mathrm{H}_{2} \mathrm{~S}$ (Figura 2) em mamíferos é catalisada, até o presente momento, via três reações enzimáticas específicas, que envolvem as enzimas cistationina-y-liase (CSE) e cistationina- $\beta$-sintase (CBS), as quais dependem do co-fator 5' piridoxal fosfato (vitamina B6), e utilizam a L-cisteína como substrato para a geração de $\mathrm{H}_{2} \mathrm{~S}$. Já a terceira via enzimática utiliza a 3- 
mercaptopiruvato sulfurtransferase (3MST), cujo substrato é o 3-mecaptopiruvato (3MP), gerado previamente pela ação da cisteína aminotransferase (CAT) sobre a cisteína e o a-cetoglutarato (Kimura, 2012; Li et al., 2011; Lowicka, Bettowski, 2007; Wang, 2002).

Figura 2 - Síntese endógena de H2S.

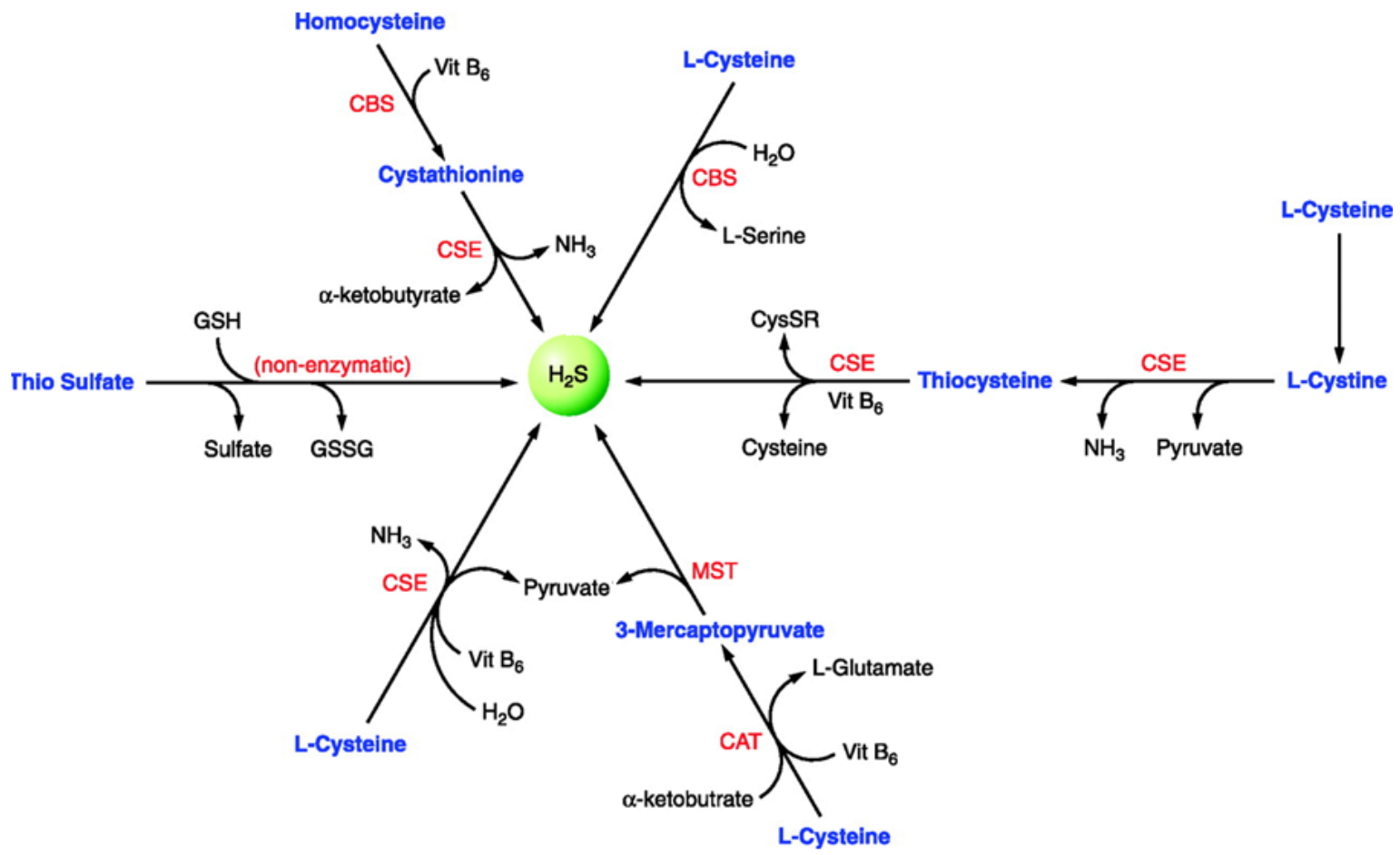

Principais vias para síntese de $\mathrm{H}_{2} \mathrm{~S}$, L-cisteína, principal substrato para geração de $\mathrm{H}_{2} \mathrm{~S}$ a partir da CBS e CSE. A via CAT/3MST foi recentemente descrita no processo. Produção não enzimática ocorre, mas não contribui significativamente para geração de $\mathrm{H}_{2} \mathrm{~S}$.

Fonte: Wang, 2012.

As enzimas geradoras de $\mathrm{H}_{2} \mathrm{~S}$ estão expressas de forma ampla em vários tecidos; muito embora a principal fonte fisiológica provedora de $\mathrm{H}_{2} \mathrm{~S}$, via CBS, ocorre no sistema nervoso central (hipocampo, cerebelo, córtex e tronco cerebral). Além disto, essa enzima encontra-se expressa nos rins, fígado e intestino (Caliendo et al., 2010; Kabil et al., 2011; Moore et al., 2003; Roy et al., 2012). Em contrapartida, a CSE encontra-se expressa preferencialmente em órgãos periféricos (ex.: aorta, artéria mesentérica, veia porta, pulmão, pâncreas, estômago, fígado, rim e sistema intrauterino) (Caliendo et al., 2010; Fiorucci et al., 2005; Fu et al., 2008; Ishii et al., 2004; Nishimura et al., 2009; Patel et al., 2009). A isoforma 3MST encontra-se 
constitutivamente expressa em órgãos periféricos como o fígado, rins, coração, pulmão, timo, testículo, cérebro e, principalmente, aorta (Caliendo et al., 2010).

Paralelo a esse conhecimento, a criação de animais nocautes para as enzimas geradoras de $\mathrm{H}_{2} \mathrm{~S}$, bem como a síntese de moléculas sintéticas doadoras de $\mathrm{H}_{2} \mathrm{~S}$, e, também, de moléculas inibidoras das enzimas responsáveis por sua síntese, têm contribuindo grandemente para uma melhor caracterização do $\mathrm{H}_{2} \mathrm{~S}$ em condições fisiológicas e patológicas (Guo et al., 2013; Li et al., 2009; Roy et al., 2012; Watanabe et al., 1995; Yang et al., 2008; Wallace et al., 2012).

Dentre a variedade de moléculas doadoras de $\mathrm{H}_{2} \mathrm{~S}$ disponíveis comercialmente para uso em pesquisa animal, estão as moléculas doadoras de $\mathrm{H}_{2} \mathrm{~S}$ de liberação lenta (ex.: GYY4137, SRHD e AP67), rápida (ex.: $\mathrm{Na}_{2} \mathrm{~S}, \mathrm{NaHS}$ e reagente de Lawesson) e, ainda, as moléculas híbridas, como o ATB346, ATB343 e ATB429, que possuem um grupamento doador de $\mathrm{H}_{2} \mathrm{~S}$ (1,2-ditiol-3-thiona) inserido em uma molécula anti-inflamatória não esteroide clássica: naproxeno, indometacina e mesalamina, respectivamente (Guo et al., 2013; Li et al., 2009; Trionnaire et al., 2012; Wallace, 2007; Wallace et al., 2012). O ATB346, recentemente, teve a Fase I de estudo clínico concluída e se demonstra promissor no controle da inflamação crônica (Antibe Therapeutics, 2015).

No que tange ao efeito protetor dos doadores de $\mathrm{H}_{2} \mathrm{~S}$ nas doenças inflamatórias, como a artrite, achados prévios deste grupo revelaram que ratos com artrite induzida por carragenina exibiram melhora significativa de parâmetros inflamatórios e nociceptivos (dor e alodinia) mediante a terapia com doadores de $\mathrm{H}_{2} \mathrm{~S}$ de liberação rápida (Reagente de Lawesson) ou com a molécula híbrida ATB346 (Ekundi-Valentim et al., 2010, 2013). Essa mesma molécula mostrou-se potente redutora da perda óssea e inflamação resultantes no modelo de periodontite em ratos (Herrera et al., 2015). Além disto, membros do grupo revelaram que camundongos com asma experimental tratados com doadores de $\mathrm{H}_{2} \mathrm{~S}$ de liberação rápida (NaHS) exibiram redução significativa da inflamação alérgica pulmonar em relação ao grupo controle com asma, via mecanismo dependente do aumento das defesas antioxidantes (Benetti et al., 2012).

Estudo em andamento do grupo demonstra que no modelo experimental de psoríase induzida por IMQ em camundongos Balb/c, alguns dos sinais clínicos da psoríase (rubor, acantose e descamação), bem como o comportamento de prurido foram amenizados de forma significativa pela terapia sistêmica diária (i.p.) com o 
doador de $\mathrm{H}_{2} \mathrm{~S}$ de liberação lenta (GYY4137; Figura 3, painéis $\left.A-D\right)$. Estes dados mostram, pela primeira vez, o potencial terapêutico dessa molécula na redução da progressão da psoríase no modelo experimental da doença (Rodrigues et al., 2015).

Figura 3 - Efeito do GYY4137 na psoríase induzida por imiquimode (IMQ) em camundongos.
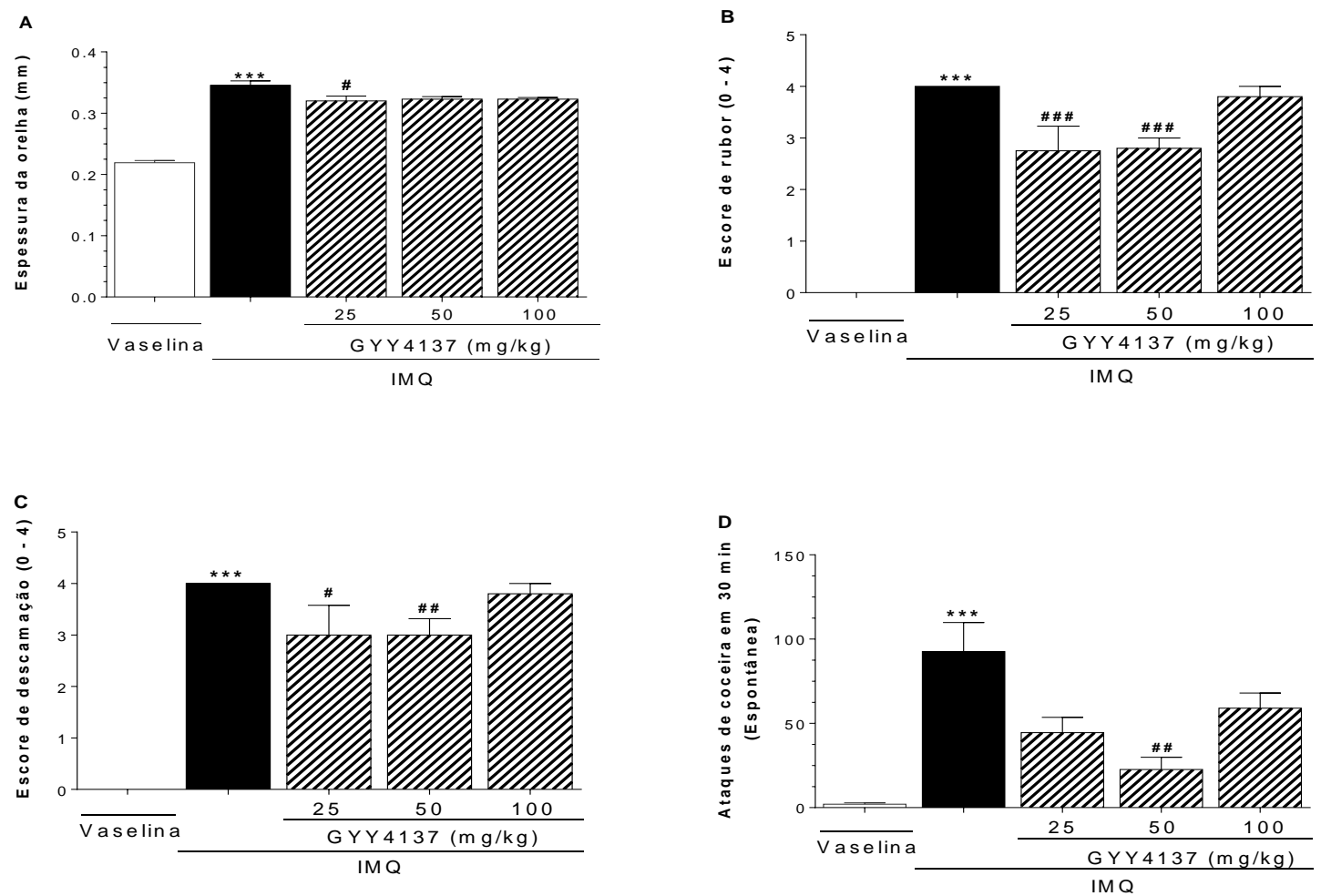

Os Painéis $A$, B e C mostram o registro no desenvolvimento da espessura, do rubor e descamação, respectivamente, induzida por IMQ na presença e ausência de diferentes doses de GYY4137. O painel $D$ ilustra o desenvolvimento de prurido sob as mesmas condições. $n=4-5$. Os dados estão apresentados como média \pm e.p.m. para $\mathrm{n}$ animais e representam análises do último dia de experimento. ${ }^{* * *} P<0.001$ vs. grupo controle-vaselina; ${ }^{\#} P<0.05{ }^{\# \#} P<0.01{ }^{\# \# \#} P<0.001$ vs. IMQ isolado (ANOVA de uma via seguida por Dunnett).

Fonte: Rodrigues et al., 2015.

Diante do exposto e no sentido de aprofundar e validar em outra via de administração o efeito protetor do GYY4137 na psoríase experimental, esta proposta pretende averiguar o potencial terapêutico de formulações tópicas nanodispersas ou microemulsões contendo a molécula GYY4137. 


\subsection{Permeação cutânea e formulações nanodispersas}

A pele é uma via de administração amplamente utilizada no tratamento de doenças tópicas, sendo que a permeação de fármacos através desse órgão pode ocorrer tanto através de apêndices, como folículos pilosos e glândulas sudoríparas, quanto pela de difusão através do extrato córneo. Contudo, a contribuição dos apêndices para a permeação é mínima, visto que eles ocupam apenas $0,1 \%$ da área total da pele (Carollo, 2011). Assim, a principal forma de permeação ocorre por difusão passiva através do extrato córneo, por meio de duas vias: a intercelular e transcelular (Moser et al., 2001). Entretanto, o extrato córneo funciona como uma barreira contra a penetração de determinadas partículas (Petrilli, 2013). Isso ocorre pois, embora essa seja a camada mais fina da epiderme, as camadas de corneócitos do extrato córneo são hermeticamente fechadas por camadas lipídicas densas, formando uma estrutura muitas vezes chamada de "tijolos e argamassa", o que confere maior resistência para o transporte de substâncias através da pele. Devido a essas barreiras, muitos fármacos têm dificuldade de se difundirem através do extrato córneo (Egawa et al., 2007).

Dessa forma, estratégias para aumentar a permeação cutânea são necessárias como, por exemplo, métodos químicos que envolvem o desenvolvimento de novos veículos e sistemas que contenham agentes promotores de absorção. Neste contexto, as microemulsões e as nanodispersões líquidocristalinas vêm apresentando vantagens promissoras, pois permitem maior poder de penetração cutânea do fármaco e, consequentemente, maior eficácia farmacológica (Bhavesh et al., 2012; Kogan, Garti, 2006; Lopes et al., 2006).

A microemulsão pode ser definida como uma dispersão coloidal opticamente isotrópica, fluida e transparente, com fase dispersa geralmente inferior a $150 \mathrm{~nm}$, e formada por mistura de tensoativo e co-tensoativo (fase oleosa e aquosa) (Danielsson, Lindman, 1981). As microemulsões não só possuem facilidade e baixo custo de preparo, mas também, apresentam maior estabilidade termodinâmica e facilitam a penetração do fármaco através do estrato córneo, aumentando assim sua penetração até as camadas mais profundas, onde várias das doenças cutâneas se desenvolvem (Kogan, Garti, 2006).

Dependendo da razão entre os componentes utilizados, é possível desenvolver três estruturas diferentes de microemulsões: água-em-óleo $(A / O)$, óleo- 
em-água (O/A) e uma estrutura intermediária, conhecida como bicontínua (Figura 4) (Damasceno et al., 2011; Kreilgaard, 2002). A microemulsão A/O é obtida quando a água é envolvida por moléculas de tensoativos em um meio contínuo de óleo como fase externa. Inversamente, no tipo O/A, a fase oleosa é envolvida por moléculas de tensoativos em um meio contínuo de água. A estrutura bicontínua é observada, por exemplo, durante a transição entre as outras fases; ou seja, quando os componentes hidrofílicos e lipofílicos estão presentes em volumes muito semelhantes, formando assim canais adjacentes alongados (Constantinides, Yiv, 1995; D`Cruz, Uckun, 2001; Kreilgaard, 2002).

Figura 4 - Tipos de microemulsões.

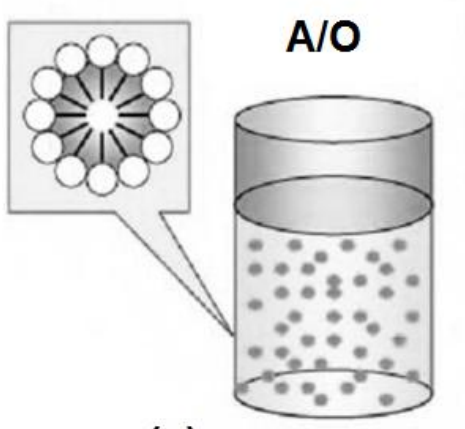

(a) Hidrofilico > Lipofilico

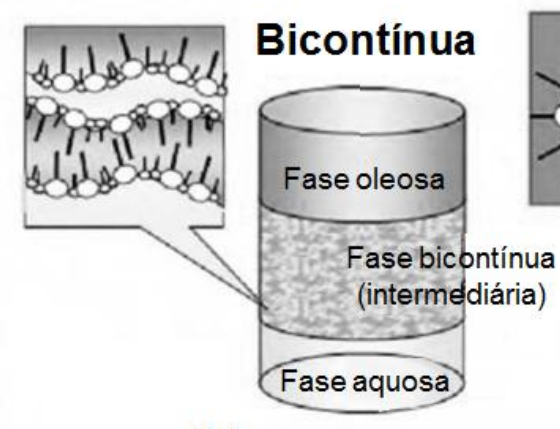

(b) Hidrofilico = Lipofilico

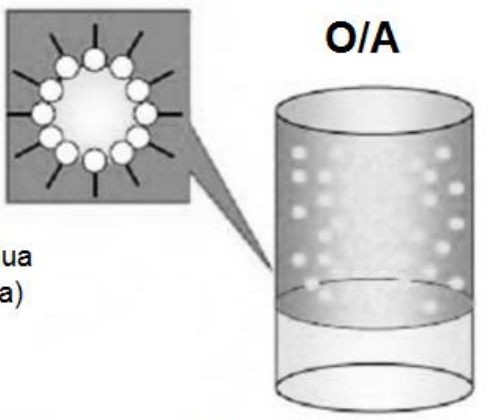

(c) Hidrofilico < Lipofilico

\section{BHL (Balanço hidrofílico-lipofílico)}

(a) Microemulsão aquosa. (b) microemulsão bicontínua. (c) microemulsão oleosa.

Fonte: Kunitake et al., 2012.

As nanodispersões líquido-cristalinas também existem em três diferentes formas: lamelar, hexagonal e cúbica (Figura 5), dependendo da temperatura e quantidade de água envolvida. A fase lamelar consiste numa disposição linear alterando bicamadas lipídicas e canais de água. A fase hexagonal consiste em hastes infinitas de água dispostas em redes entrelaçadas bidimensionalmente e separadas por bicamadas lipídicas. Esta fase é obtida apenas em temperaturas elevadas, ou então pela adição de um terceiro componente apolar, como o ácido oleico, que além de conferir essa característica à formulação, também apresenta capacidade de sustentar a entrega dos compostos incorporados. Já a fase cúbica é um estágio de transição entre a fase lamelar e hexagonal (Ferreira et al., 2006; Lopes et al., 2006). 
Figura 5 - Estruturas das nanodispersões líquido-cristalinas.

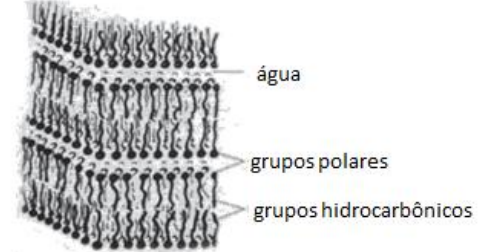

(a) Lamelar

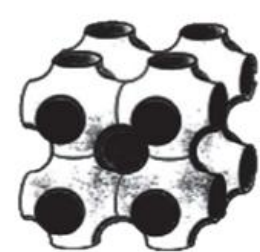

(b) Cúbica

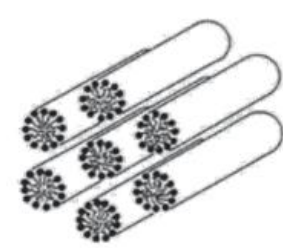

(c) Hexagonal

(a) Fase lamelar. (b) fase cúbica (intermediária). (c) Fase hexagonal.

Fonte: Formariz et al., 2005.

Dentre as vantagens desse tipo de formulação destacam-se: facilidade do preparo, proteção a termo e fotodegradação, promoção do aumento da retenção de água no extrato córneo, contribuindo dessa forma para o aumento da hidratação cutânea e ainda, promoção do aumento da solubilidade e/ou difusibilidade do fármaco através do extrato córneo, resultando em um maior efeito farmacológico da nanodispersão (Carollo, 2011; Petrilli, 2013). 


\section{CONCLUSÕES}

1. A nanodispersão de fase líquido-cristalina se mostrou, dentre as cinco formulações testadas, a mais compatível com a pele murina para entrega da molécula doadora de $\mathrm{H}_{2} \mathrm{~S}$ de liberação lenta, o GYY4137, pois além de exibir características físico-químicas estáveis não promoveu irritação cutânea;

2. A terapia tópica diária, uma vez/dia, com a nanodispersão contendo GYY4137 (4\%) reduziu significativamente parâmetros relacionados à psoríase, tais como PASI, infiltrado neutrofílico (mensurado via atividade da MPO) e aumento das concentrações de citocinas inflamatórias na pele;

3. A aplicação tópica da mesma preparação contendo GYY4137 (4\%), duas vezes ao dia (12/12 h), superou a ação protetora observada com a aplicação diária única dessa formulação sobre os sinais e sintomas da psoríase, indicando assim um potencial terapêutico para o GYY4137 incorporado a nanodispersão;

4. A geração basal de sulfeto de hidrogênio na pele murina com psoríase foi significativamente menor em relação a geração do animal controle; todavia, esta redução foi parcialmente revertida pela suplementação exógena com a nanodispersão contendo GYY4137;

5. As ações terapêuticas da administração tópica diária com a nanodispersão contendo GYY4137 (4\%), 12/12 h, sobre os sinais e sintomas da psoríase assemelham-se às ações da nanodispersão contendo dexa (4\%), exceto que a primeira mostrou um perfil de segurança mais elevado, visto que os efeitos sistêmicos foram menos pronunciados;

6. Conclui-se que o GYY4137 incorporado a nanodispersão possui potencial terapêutico importante para o controle e redução dos sinais e sintomas da psoríase e, portanto, novos estudos de mecanismos envolvidos devem ser considerados. 


\section{REFERÊNCIAS ${ }^{1}$}

Alshorafa AKH, Guo Q, Zeng F, Chen M, Tan G, Tang Z, Yin R. Psoriasis is associated with low serum levels of hydrogen sulfide, a potential anti-inflammatory molecule. Tohoku $\mathrm{J}$ Exp Med 2012;(228):325-32.

Amatya B, El-Nour H, Holst M, Theodorsson E, Nordlind K. Expression of tachykinins and their receptors in plaque psoriasis with pruritus. Br J Dermatol. 2011;164(5):1023-9.

Andrés RM, Payá M, Montesinos MC, Ubeda A, Navalón P, Herrero M, Vergés J, Terencio MC. Potential antipsoriatic effect of chondroitin sulfate through inhibition of NF-KB and STAT3 in human keratinocytes. Pharmacol Res. 2013;70(1):20-6.

Antibe Therapeutics. Antibe Therapeutics provides an update on its data review and corporate strategy.

Disponível

em:

<http://www.antibethera.com/s/PressReleases.asp?ReportID=699894\&_Type=Press-

Releases\&_Title=ANTIBE-THERAPEUTICS-PROVIDES-AN-UPDATE-ON-ITS-DATA-REVIEW-ANDCORPORATE-STR...> Acesso em: 13 mar. 2015.

Baek JO, Byamba D, Wu WH, Kim TG, Lee MG. Assessment of an imiquimod-induced psoriatic mouse model in relation to oxidative stress. Arch Dermatol Res. 2012;304(9):699-706.

Barry, B. W. Dermatological formulations: percutaneous absorption. Marcel Dekker, New York, 1983.

Benetti LR, Campos D, Gurgueira SA, Vercesi AE, Guedes CE, Santos KL, Wallace JL, Teixeira SA, Florenzano J, Costa SK, Muscará MN, Ferreira HH. Hydrogen sulfide inhibits oxidative stress in lungs from allergic mice in vivo. Eur J Pharmacol. 2013;698(1-3):463-9.

Beyer V, Wolverton SE. Recent trends in systemic psoriasis treatment costs. Arch Dermatol. 2010;146(1):46-54.

Bhavesh S, Barot PB, Parejiya HK, Patel MC, Gohel PKS. Microemulsion-Based Gel of Terbinafine for the Treatment of Onychomycosis: Optimization of Formulation Using D-Optimal Design. AAPS PharmSciTech. 2012;13(1):184-92.

Blumberg $\mathrm{H}$, Dinh $\mathrm{H}$, Trueblood ES et al. Opposing activities of two novel members of the IL-1 ligand family regulate skin inflammation. J Exp Med. 2007;(204):2603-261.

Bonventre JV, Vaidya VS, Schmouder R, Feig P, Dieterle F. Next-generation biomarkers for detecting kidney toxicity. Nat Biotechnol. 2010; 28(5):436-40.

Bos JD, de Rie MA, Teunissen MB, Piskin G. Psoriasis: dysregulation of innate immunity. $\mathrm{Br} \mathrm{J}$ Dermatol. 2005; 152(6):1098-107.

Caliendo G, Cirino G, Santagada V, Wallace JL. Synthesis and biological effects of hydrogen sulfide (H2S): development of H2S-releasing drugs as pharmaceuticals. J Med Chem. 2010;(53):6275-86.

Capek I. Degradation of kinetically-stable o/w emulsions. Adv Colloid Interface Sci. 2004; 19;107(23):125-55.

Carollo, ARH. Influência do ácido oleico como promotor de absorção cutânea para o ácido 5aminolevulínico na terapia fotodinâmica do cancer de pele: estudos in vitro e in vivo em modelo animal. [Dissertação (Mestrado em medicamentos e cosméticos) ]. Ribeirão Preto: Faculdade de Ciências Farmacêuticas de Ribeirão Preto, Universidade de São Paulo; 2007.

\footnotetext{
${ }^{1}$ De acordo com: International Committee of Medical Journal Editors. [Internet]. Uniform requirements for manuscripts submitted to Biomedical Journal: sample references. [updated $2011 \mathrm{Jul} 15$ ]. Available from: http://www.icmje.org
} 
Carrier Y, Ma HL, Ramon HE, Napierata L, Small C, O'Toole M, Young DA, Fouser LA, NickersonNutter C, Collins M, Dunussi-Joannopoulos K, Medley QG. Inter-regulation of Th17 cytokines and the IL-36 cytokines in vitro and in vivo: implications in psoriasis pathogenesis. J Invest Dermatol. 2011;131(12):2428-37.

Carubbi C, Gobbi G, Bucci G, Gesi M, Vitale M, Mirandola P. Skin, inflammation and sulfurous waters: what is known, what is believed. European Journal of Inflammation. $2013: 11(3): 591-99$.

Castela E, Archier E, Devaux S, Gallini A, Aractingi S, Cribier B, Jullien D, Aubin F, Bachelez H, Joly P, Le Maître M, Misery L, Richard M-A, Paul C, Ortonne JP. Topical corticosteroids in plaque psoriasis: a systematic review of risk of adrenal axis suppression and skin atrophy. Journal of the European Academy of Dermatology and Venereology. 2012;26:47-51.

Cevikbas F, Wang X, Akiyama T, Kempkes C, Savinko T, Antal A, Kukova G, Buhl T, Ikoma A, Buddenkotte J, Soumelis V, Feld M, Alenius H, Dillon SR, Carstens E, Homey B, Basbaum A, Steinhoff M. A sensory neuron-expressed IL-31 receptor mediates $T$ helper cell-dependent itch: Involvement of TRPV1 and TRPA1. J Allergy Clin Immunol. 2014;133(2):448-60.

Chen YH, Wu R, Geng B, Qi YF, Wang PP, Yao WZ, Tang CS. Endogenous hydrogen sulfide reduces airway inflammation and remodeling in a rat model of asthma.Cytokine. 2009; 45(2):117-23.

Chi C-C, Wang S-H. Efficacy and cost-efficacy of biologic therapies for moderate to severe psoriasis: a meta-analysis and cost-efficacy analysis using the intention-to-treat principle. BioMed Research International. 2014;2014:862851.

Cohen SN, Baron SE, Archer CB; British Association of Dermatologists and Royal College of General Practitioners. guidance on the diagnosis and clinical management of psoriasis. Clin Exp Dermatol. 2012;37 Suppl 1:13-8.

Constantinides PP, YIV SH. Particle-size determination of phase-inverted water-in-oil microemulsion sunder different dilutionand storage-conditions. Int J Pharm. 1995:7;115(2):225-34.

Correa MA, Scarpa MV, Franzini MC, Oliveira AG. On the incorporation of the non-steroidal antiinflammatory naproxen into cationic O/W microemulsions. Colloids Surf B Biointerfaces. 2005:25;43(2):108-14.

Costa SK, Starr A, Hyslop S, Gilmore D, Brain SD. How important are NK1 receptors for influencing microvascular inflammation and itch in the skin? Studies using Phoneutria nigriventer venom. Vascul Pharmacol. 2006;45(4):209-14.

Cremonez CP, Bentley MVLB, Lara MG. Caracterização do intumescimento de sistemas líquidocristalinos de fase lamelar demonoleína e água contendo polihexametilenobiguanida. Rev Ciênc Farm Básica Apl. 2014;34(4):545-53.

Crow JM. Psoriasis uncovered. Nature. 2012:20;492(7429):S50-1.

Cunha TM, Dal-Secco D, Verri WA Jr, Guerrero AT, Souza GR, Vieira SM, Lotufo CM, Neto AF, Ferreira SH, Cunha FQ. Dual role of hydrogen sulfide in mechanical inflammatory hypernociception. Eur J Pharmacol. 2008;590(1-3):127-35.

Damasceno BPGL, Silva JÁ, Oliveira EE, Silveira WLL, Araújo IB; Oliveira AG; Egito EST. Microemulsão: um promissor carreador para moléculas insolúveis. Rev Ciênc Farm Básica Apl. $2011 ; 32(1): 9-18$.

Danielsson I, Lindman B. The definition of microemulsion. Colloid Surf. 1981;(3):391-2.

Darmstadt GL, Badrawi N, Law PA, Ahmed S, Bashir M, Iskander I, et al. Topically applied sunflower seed oil prevents invasive bacterial infections in preterm infants in Egypt: a randomized, controlled clinical trial. Pediatr Infect Dis J. 2004;23:719-25.

D'Cruz OJ, Uckun FM. Gel-microemulsions as vaginal spermicides and intravaginal drug delivery vehicles. Contraception. 2001;64(2):113-23. 
Debets R, Timans JC, Homey B, Zurawski S, Sana TR, Lo S, Wagner J, Edwards G, Clifford T, Menon $\mathrm{S}$, Bazan JF, Kastelein RA. Two novel IL-1 family members, IL-1 delta and IL-1 epsilon, function as an antagonist and agonist of NF-kappa B activation through the orphan IL-1 receptor-related protein 2. J Immunol. 2001;167(3):1440-6.

Di Meglio P, Perera GK, Nestle FO. The multitasking organ: recent insights into skin immune function. Immunity. 2011; 35(6):857-69.

Diamantino F, Ferreira A. Perspectivas futuras no tratamento da psoríase: novidades em terapêutica biológica. Acta Med Port 2012;(24):997-1004.

Dumortier G, Grossiord JL, Agnely F, Chaumeil JC. A review of poloxamer 407 pharmaceutical and pharmacological characteristics. Pharm Res. 2006;23(12):2709-28.

Dunford PJ, Williams KN, Desai PJ, Karlsson L, McQueen D, Thurmond RL. Histamine H4 receptor antagonists are superior to traditional antihistamines in the attenuation of experimental pruritus. $J$ Allergy Clin Immunol. 2007;119(1):176-83.

Egawa M, Hirao T, Takahashi M. In vivo estimation of stratum corneum thickness from water concentration profiles obtained with Raman spectroscopy. Acta Derm Venereol. 2007;87(1):4-8.

Ekundi-Valentim E, Mesquita FP, Santos KT, de Paula MA, Florenzano J, Zanoni Cl, Rodrigues L, de Nucci G, Teixeira SA, Ferreira HH, Wallace JL, Costa SK, Muscará MN. A comparative study on the anti-inflammatory effects of single oral doses of naproxen and its hydrogen sulfide (H2S)-releasing derivative ATB-346 in rats with carrageenan-induced synovitis. Med Gas Res. 2013;3(1):24.

Ekundi-Valentim E, Santos KT, Camargo EA, Denadai-Souza A, Teixeira SA, Zanoni Cl, Grant AD, Wallace J, Muscará MN, Costa SK. Differing effects of exogenous and endogenous hydrogen sulphide in carrageenan-induced knee joint synovitis in the rat. $\mathrm{Br} \mathrm{J}$ Pharmacol. 2010;159(7):1463-74.

Faria, RM et al. Effect of dexamethasone on the leukogram of healthy sheep. Semina: Ciências Agrárias. 2014;34(6Supl2)3739-46.

Fiorucci S, Antonelli E, Distrutti E, Rizzo G, Mencarelli A, Orlandi S, Zanardo R, Renga B, Di Sante M, Morelli A, Cirino G, Wallace JL. Inhibition of hydrogen sulfide generation contributes to gastric injury caused by anti-inflammatory nonsteroidal drugs. Gastroenterology. 2005;129(4):1210-24.

Flutter B, Nestle FO. TLRs to cytokines: mechanistic insights from the imiquimod mouse model of psoriasis. Eur J Immunol. 2013;43(12):3138-46.

Fu Z, Liu X, Geng B, Fang L, Tang C. Hydrogen sulfide protects rat lung from ischemia-reperfusion injury. Life Sci. 2008;82(23-24):1196-202.

Furst DE. Update on psoriatic arthritis: epidemiology, pathogenesis, clinical assessment and treatment. Revista Latinoamericana de Psoriasis y Artritis Psoriásica. 2011;3:25-59.

Formariz $T$, Urban $M$, Silva Júnior $A$, Gremião $M$, Oliveira $A$. Microemulsões e fases líquidas cristalinas como sistemas de liberação de fármacos. Revista Brasileira de Ciências Farmacêuticas. 2005:41(3), 301-13.

Gangemmi S, Franchina T, Minciullo PL, Profita M, Zanghì M, David A, Kennez I, Adamo V. IL-33/LL31 axis: a new pathological mechanisms for EGFR tyrosine kinase inhibitors-associated skin toxicity. $J$ Cell Biochem. 2013;114(12):2673-6.

Garden JM, Freinkel RK. Systemic absorption of topical steroids. Metabolic effects as an index of mild hypercortisolism. Arch Dermatol. 1986;122(9):1007-10.

Gottlieb AB, Dann F. Comorbidities in patients with psoriasis. Am J Med. 2009;122(12):1150.e1-9.

Guo W, Cheng Z, Zhu Y. Hydrogen sulfide and translational medicine. Acta Pharmacologica Sinica. 2013;(34):1284-91. 
Gupta MA, Gupta AK, Kirby S et al. Pruritus in psoriasis. A prospective study of some psychiatric and dermatologic correlates. Arch Dermatol 1988; (124):1052 \pm 7 .

Hathout RM, Mansour S, Mortada ND, Geneidi AS, Guy RH. Uptake of microemulsion components into the stratum corneum and their molecular effects on skin barrier function. Molecular Pharmaceutics. 2010;7(4):1266-73.

Herrera BS, Coimbra LS, da Silva AR, Teixeira SA, Costa SK, Wallace JL, Spolidorio LC, Muscara MN. The H2S-releasing naproxen derivative, ATB-346, inhibits alveolar bone loss and inflammation in rats with ligature-induced periodontitis. Med Gas Res. 2015: 27;5:4.

Hine C, Harputlugil E, Zhang Y, Ruckenstuhl C, Lee BC, Brace L, Longchamp A, Treviño-Villarreal JH, Mejia P, Ozaki CK, Wang R, Gladyshev VN, Madeo F, Mair WB, Mitchell JR. Endogenous hydrogen sulfide production is essential for dietary restriction benefits. Cell. 2015:15;160(1-2):132-44.

Ikoma A, Handwerker H, Miyachi Y, Schmelz M. Electrically evoked itch in humans. Pain. 2005;113(12):148-54.

Ishii I, Akahoshi N, Yu XN, Kobayashi Y, Namekata K, Komaki G, Kimura H. Murine cystathionine gamma-lyase: complete cDNA and genomic sequences, promoter activity, tissue distribution and developmental expression. Biochem J. 2004;381(Pt 1):113-23.

Iwaniszczuk A, Kulinski W. Optimization of balneophysiotherapy in psoriasis vulgaris. Acta Balneol.2013;1(131):5-122013.

Jafarl SM, Assadpoor E, He Y, Bhandari B. Re-coalescence of emulsion droplets during high-energy emulsification. Food Hydrocolloids, 2008:22:1191- 1202.

Johnston A, Xing X, Guzman AM, Riblett M, Loyd CM, Ward NL, Wohn C, Prens EP, Wang F, Maier LE, Kang S, Voorhees JJ, Elder JT, Gudjonsson JE. IL-1F5, -F6, -F8, and -F9: a novel IL-1 family signaling system that is active in psoriasis and promotes keratinocyte antimicrobial peptide expression. J Immunol. 2011;186(4):2613-22.

Kabil O, Vitvitsky $\mathrm{V}$, Xie P, Banerjee R. The quantitative significance of the transsulfuration enzymes for H2S production in murine tissues. Antioxid Redox Signal. 2011;15(2):363-72.

Kimura H. Metabolic turnover of hydrogen sulfide. Front Physiol. 2012;3:101.

Kogan A, Garti N. Microemulsions as transdermal drug delivery vehicles. Adv Colloid Interface Sci. 2006;(123-126):369-85.

Krauel K, Graf A, Hook SM, Davies NM, Rades T. Preparation of poly (alkylcyanoacrylate) nanoparticles by polymerization of water-free microemulsions. J Microencapsul. 2006 Aug;23(5):499512.

Kreilgaard M. Influence of microemulsions on cutaneous drug delivery. Adv Drug Deliv Rev. 2002;54(1):77-98.

Kroesen S, Widmer AF, Tyndall A, Hasler P. Serious bacterial infections in patients with rheumatoid arthritis under anti-TNF-alpha therapy. Rheumatology (Oxford). 2003;42(5):617-21.

Krueger JG, Bowcock A. Psoriasis pathophysiology: current concepts of pathogenesis. Ann Rheum Dis 2005; 64(Suppl II):ii30-ii36, 2005.

Kunitake M, Sakata K, Nishimi T. Mesostructured polymer materials based on bicontinuous microemulsions, Microemulsions - An Introduction to Properties and Applications, Dr. Reza Najjar (Ed.), ISBN: 978-953-51-0247-2, 2012.

Kuryłowicz A, Nauman J. The role of nuclear factor-kappaB in the development of autoimmune diseases: a link between genes and environment. Acta Biochim Pol. 2008;55(4):629-47. 
Langley RG, Krueger GG, Griffiths CE. Psoriasis: epidemiology, clinical features, and quality of life. Ann Rheum Dis. 2005; 64(Suppl II):ii18-ii23.

Lawrence MJ, Rees GD. Microemulsion-based media as novel drug delivery systems. Adv Drug Deliv Rev. 2000:6;45(1):89-121

Lessmann H, Schnuch A, Geier J, Uter W. Skin-sensitizing and irritant properties of propylene glycol. Contact Dermatitis. 2005;53(5):247-59.

Li L, Rose P, Moore PK. Hydrogen sulfide and cell signaling. Annu Rev Pharmacol Toxicol. 2011; (51):169-87.

Li L, Salto-Tellez M, Tan CH, Whiteman M, Moore PK. GYY4137, a novel hydrogen sulfide-releasing molecule, protects against endotoxic shock in the rat. Free Radic Biol Med. 2009;1:47(1):103-13.

Li L, Whiteman M, Guan YY, Neo KL, Cheng Y, Lee SW, Zhao Y, Baskar R, Tan CH, Moore PK. Characterization of a novel, water-soluble hydrogen sulfide-releasing molecule (GYY4137): new insights into the biology of hydrogen sulfide. Circulation. 2008;117(18):2351-60.

Li WQ, Han JL, Zhang MF, Qureshi AA. Interactions between adiposity and genetic polymorphisms on the risk of psoriasis. Br J Dermatol. 2013;168(3):639-42.

Liles WC, Dale DC, Klebanoff SJ. Glucocorticoids inhibit apoptosis of human neutrophils. Blood. 1995: $15 ; 86(8): 3181-8$.

Lima EA, Lima MA. Imunoptogênese da psoríase: revisando conceitos. An Bras Dermatol. 2011; 86(6):1151-8.

Loden M, Buraczewska I, Edlund F. Irritation potential of bath and shower oils before and after use: a double-blind randomized study. Br J Dermatol. 2004;150:1142-7.

Lopes LB, Lopes JL, Oliveira DC, Thomazini JA, Garcia MT, Fantini MC, Collett JH, Bentley MV. Liquid crystalline phases of monoolein and water for topical delivery of cyclosporin A: characterization and study of in vitro and in vivo delivery. Eur J Pharm Biopharm. 2006;63(2):146-55.

Lopes LB, Speretta FF, Bentley MV. Enhancement of skin penetration of vitamin K using monooleinbased liquid crystalline systems. Eur J Pharm Sci. 2007;32(3):209-15.

Lowicka E, Bettowski. Hydrogen sulfide ( $\mathrm{H} 2 \mathrm{~S}$ ) - the third gas of interest for pharmacologists. Pharmacological Reports. 2007;(59):4-24.

Mabuchi T, Chang TW, Quinter S, Hwang ST. Chemokine receptors in the pathogenesis and therapy of psoriasis. J Dermatol Sci. 2012;65(1):4-11.

Magitz H, Orion E, Wof R. Balneotherapy in dermatology. Dermatologic Therapy. 2003;16:132-140.

Man XY, Li W, Chen JQ, Zhou J, Landeck L, Zhang KH, Mu Z, Li CM, Cai SQ, Zheng M. Impaired nuclear translocation of glucocorticoid receptors: novel findings from psoriatic epidermal keratinocytes. Cell Mol Life Sci. 2013;70(12):2205-20.

Marrakchi S, Guigue P, Renshaw BR, Puel A, Pei XY, Fraitag S, Zribi J, Bal E, Cluzeau C, Chrabieh M, Towne JE, Douangpanya J, Pons C, Mansour S, Serre V, MakniH, Mahfoudh N, Fakhfakh F, Bodemer C, Feingold J, Hadj-Rabia S, Favre M, Genin E,Sahbatou M, Munnich A, Casanova JL, Sims JE, Turki H, Bachelez H, Smahi A.Interleukin-36-receptor antagonist deficiency and generalized pustular psoriasis.N Engl J Med. 2011;365(7):620-8.

Martino A, Kaler EW. Phase behavior and microstructure of nonaqueous microemulsions. Langmuir, 1995;11(3):779-84.

Mathur M, Kedia S, Chimire R. An intravenous biological therapy for psoriasis: Infliximab. Journal of College of Medical Sciences-Nepal. 2011;7(1):69-72. 
Mazzulla S, Nicoletta V, Perrotta I, Stefano S, Sesti S. In vivo study of biomechanical properties in psoriasis vulgaris: Effectiveness of sulfur spa therapy. Open Journal of Molecular and Integrative Physiology. 2013;03(01):15-20.

McGlone F, Reilly D. The cutaneous sensory system. Neurosci Biobehav Rev. 2010;34(2):148-59.

Mirandola P, Gobbi G, Sponzilli I, Pambianco M. Exogenous hydrogen sulfide induces functional inhibition and cell death of cytotoxic lymphocytes subsets. Journal of Cellular Physiology. 2007;213:826-833.

Moser K, Kriwet K, Naik A, Kalia YN, Guy RH. Passive skin penetration enhancement and its quantification in vitro. Eur J Pharm Biopharm. 2001;52(2):103-12.

Moore PK, Bhatia M, Moochhala S. Hydrogen sulfide: from the smell of the past to the mediator of the future? Trends Pharmacol Sci. 2003;24(12):609-11.

Mrowietz U, Kragballe K, Reich K, Spuls P, Griffiths CEM, et al. Definition of treatment goals for moderate to severe psoriasis: a European consensus. Arch. Dermatol. Res. 2011;(303):1-10.

Naldi L. Risk factors for psoriasis. Curr Derm Rep. 2013;(2):58-65.

Narbutt J, Olejniczak I, Sobolewska-Sztychny D, Sysa-Jedrzejowska A, Słowik-Kwiatkowska I, Hawro T, Lesiak A. Narrow band ultraviolet B irradiations cause alteration in interleukin-31 serum level in psoriatic patients. Arch Dermatol Res. 2013;305(3):191-5.

Nasermoaddeli A e Kagamimori S. Balneo- therapy in medicine: a rewiew. Environmental Health and Preventive Medicine. 2005;10:171-9.

Neis MM, Peters B, Dreuw A, Wenzel J, Bieber T, Mauch C, Krieg T, Stanzel S, Heinrich PC, Merk HF, Bosio A, Baron JM, Hermanns HM. Enhanced expression levels of IL-31 correlate with IL-4 and IL-13 in atopic and allergic contact dermatitis. J Allergy Clin Immunol. 2006;118(4):930-7.

Nestle FO, Kaplan DH, Barker J. Mechanisms of disease Psoriasis. N Engl J Med. 2009;(361):496509.

Newbold PCH. Pruritus in psoriasis. In: Farber EM, Cox AJ, editors. Psoriasis: Proceedings of the Second International Symposium. New York: Yorke Medical Books; 1977. p. 334-6.

Nishimura S, Fukushima O, Ishikura H, Takahashi T, Matsunami M, Tsujiuchi T, Sekiguchi F, Naruse M, Kamanaka Y, Kawabata A. Hydrogen sulfide as a novel mediator for pancreatic pain in rodents. 2009;58(6):762-70.

Nobbe S, Dziunycz P, Mühleisen B, Bilsborough J, Dillon SR, French LE, Hofbauer GF. IL-31 expression by inflammatory cells is preferentially elevated in atopic dermatitis. Acta Derm Venereol. 2012;92(1):24-8.

Nograles KE, Davidovici B, Krueger JG. New insights in the immunologic basis of psoriasis. Semin Cutan Med Surg. 2010;29(1):3-9.

Ozer J, Ratner M, Shaw M, Bailey W, Schomaker S. The current state of serum biomarkers of hepatotoxicity. Toxicology. 2008:20;245(3):194-205.

Parisi R, Symmons DP, Griffiths CE, Ashcroft DM. Global epidemiology of psoriasis: a systematic review of incidence and prevalence. J Invest Dermatol. 2013;133(2):377-85.

Patel D, Welsh D, Baker M. Comparative study of propyleneglycol and caprylic/capric triglyceride vehicles for topical application. J Soc Cosmet Chem. 1985;36:303-11.

Patel P, Vatish M, Heptinstall J, Wang R, Carson RJ. The endogenous production of hydrogen sulphide in intrauterine tissues. Reprod Biol Endocrinol. 2009;7:10.

Pepe D, Mccall M, Zheng H, Lopes LB: Protein transduction domain-containing microemulsions as cutaneous delivery systems for an anticancer agent. J Pharm Sci. 2013;102(5):1476-87. 
Pepe D, Phelps J, Lewis K, et al. Decylglucoside-based microemulsions for cutaneous localization of lycopene and ascorbic acid. Int J Pharm. 2012;434(1-2):420-8.

Perera GK, Di Meglio P, Nestle FO. Psoriasis. Annu Rev Pathol Mech Dis. 2012;(7):385-422.

Petri B, Phillipson M, Kubes $\mathrm{P}$. The physiology of leukocyte recruitment: an in vivo perspective. $J$ Immunol. 2008;180(10):6439-46.

Petrilli, R. Nanopartículas de fase líquido-cristalina hexagonal funcionalizadas com peptídeos de transdução para veiculação do siRNA na terapia de doenças tópicas. [Dissertação (Mestrado em medicamentos e cosméticos) ]. Ribeirão Preto: Faculdade de Ciências Farmacêuticas da Universidade de São Paulo, 2013.

Rabenhorst A, Hartmann K. Interleukin-31: a novel diagnostic marker of allergic diseases. Curr Allergy Asthma Rep. 2014;14(4):423.

Reich A, Szepietowski JC. Mediators of pruritus in psoriasis. Mediators of Inflamm. 2007;2007:64727.

Rodrigues AP, Teixiera RM. Desvendando a psoríase. RBAC. 2009;41(4):303-9.

Rodrigues L, Schmidt TR, Florenzano J, dos Santos KT, Cerqueira ARA, Teixeira SA, Wood ME, Whiteman M, Muscara MN, Costa SKP The slow-releasing hydrogen sulphide donor, GYY4137, exhibits novel anti-skin symptoms of psoriasis and related itch. Nitric Oxide, Volume 47, Supplement, 1 May 2015, Page S35, ISSN 1089-8603. 3rd European Conference on the Biology of Hydrogen Sulfide, 2015, Athens. Greece. 3rd-6th May 2015.

Roy A, Khan AH, Islam MT, Prieto MC, Majid DS. Interdependency of cystathione $y$-lyase and cystathione $\beta$-synthase in hydrogen sulfide-induced blood pressure regulation in rats. Am J Hypertens. 2012;25(1):74-81.

Sainte-Laudy J. Etude du pouvoir anti-degranu- lant de l'eau d'avene vis-à-vis de basophiles humains sensibilièe. International Journal of Immunotherapy. 1987;4:307-12.

Sanchez APG. Imunopatogênese da psoríase. An Bras Dermatol. 2010;85(5):747-9.

SBD - Sociedade Brasileira de Dermatologia. Consenso Brasileiro de Psoríase 2012. Disponível em: <http://www.sbd.org.br/medicos/associado/ConsensoPso.aspx> Acesso em: 20 jan. 2014.

Schön MP, Boehncke HW. Psoriasis. N Engl J Med. 2005;(352):1899-912.

Shai A, Maibach HI, Baran R. Handbook of Cosmetic Skin Care. Informa UK Ltd., Second Edition, p. 34-40, 2009.

Shibata S, Tada Y, Asano Y, Yanaba K, Sugaya M, Kadono T, Kanda N, Watanabe S, Sato S. IL-27 activates Th1-mediated responses in imiquimod-induced psoriasis-like skin lesions. J Invest Dermatol. 2013;133(2):479-88.

Sidhapuriwala JN, Ng SW, Bhatia M. Effects of hydrogen sulfide on inflammation in caerulein-induced acute pancreatitis. J Inflamm (Lond). 2009;6:35.

Singh JA, Wells GA, Christensen R, Tanjong Ghogomu E, Maxwell L, Macdonald JK, Filippini G, Skoetz N, Francis D, Lopes LC, Guyatt GH, Schmitt J, La Mantia L, Weberschock T, Roos JF, Siebert $\mathrm{H}$, Hershan S, Lunn MP, Tugwell P, Buchbinder R. Adverse effects of biologics: a network metaanalysis and Cochrane overview. Cochrane Database Syst Rev. 2011;16(2):CD008794.

Sonkoly E, Muller A, Lauerma Al, Pivarcsi A, Soto H, Kemeny L, Alenius H, Dieu-Nosjean MC, Meller S, Rieker J, Steinhoff M, Hoffmann TK, Ruzicka T, Zlotnik A, Homey B. IL-31: a new link between T cells and pruritus in atopic skin inflammation. J Allergy Clin Immunol. 2006;117(2):411-7.

Spencer PJ. New toxicity data for the propylene glycol ethers - a commitment to public health and safety. Toxicol Lett. 2005; 28;156(1):181-8. 
Sun J, Dou W, Zhao Y, Hu J. A comparison of the effects of topical treatment of calcipotriol, camptothecin, clobetasol and tazarotene on an imiquimod-induced psoriasis-like mouse model. Immunopharmacol Immunotoxicol. 2014;36(1):17-24.

Suppasansatorn P, Nimmannit U, Conway BR, Du L, Wang Y: Microemulsions as topical delivery vehicles for the anti-melanoma prodrug, temozolomide hexyl ester (TMZA-HE). J Pharm Pharmacol., 2007; 59(6):787-94.

Szepietowski JC, Reich A, Wisnicka B. Itching in patients suffering from psoriasis. Acta Dermatovenereol Croat, 2002;(10):221-6.

Takaoka A, Arai I, Sugimoto M, Honma Y, Futaki N, Nakamura A, Nakaike S. Involvement of IL-31 on scratching behavior in NC/Nga mice with atopic-like dermatitis. Exp Dermatol. 2006;15(3):161-7.

Tortola L, Rosenwald E, Abel B, Blumberg H, Schäfer M, Coyle AJ, Renauld JC, Werner S, Kisielow J, Kopf M. Psoriasiform dermatitis is driven by IL-36-mediated DC-keratinocyte crosstalk. J Clin Invest. 2012;122(11):3965-76.

Tortora GJ. Corpo Humano: fundamentos de anatomia e fisiologia. 6ed. Porto Alegre: Artmed, 2006. $718 p$.

Towne JE, Garka KE, Renshaw BR, Virca GD, Sims JE. Interleukin (IL)-1F6, IL-1F8, and IL-1F9 signal through IL-1Rrp2 and IL-1RAcP to activate the pathway leading to NF-kappaB and MAPKs. J Biol Chem. 2004;279(14):13677-88.

Towne JE, Sims JE. IL-36 in psoriasis. Curr Opin Pharmacol. 2012;12(4):486-90.

Trionnaire SL, Whatmore J, Perry A, Wood ME, Whiteman M. P67 Slow release H2S donors protect human microvascular endothelial cells from oxidative stress induced cell death: Markedly increased potency by mitochondria-targeting. Nitric Oxide. 2012. 27(2):S40-S41.

Uva L, Miguel D, Pinheiro C, Antunes J, Cruz D, Ferreira J, Filipe P. Mechanisms of action of topical corticosteroids in psoriasis. Int J Endocrinol. 2012;2012:561018.

van der Fits L, Mourits S, Voerman JS, Kant M, Boon L, Laman JD, Cornelissen F, Mus AM, Florencia E, Prens EP, Lubberts E. Imiquimod-induced psoriasis-like skin inflammation in mice is mediated via the IL-23/IL-17 axis. J Immunol. 2009;182(9):5836-45.

Vigne S, Palmer G, Martin P, Lamacchia C, Strebel D, Rodriguez E, Olleros ML, Vesin D, Garcia I, Ronchi F, Sallusto F, Sims JE, Gabay C. IL-36 signaling amplifies Th1 responses by enhancing proliferation and Th1 polarization of naive CD4+ T cells. Blood. 2012;120(17):3478-87.

Wahlgren CF. Measurement of itch. Semin Dermatol. 1995;14(4):277-84

Wallace JL, Ferraz JGP, Muscará MN. Hydrogen Sulfide: An Endogenous Mediator of Resolution of Inflammation and Injury. Antioxid. Redox Signal. 2012;17(1):58-67.

Wallace JL. Hydrogen sulfide-releasing anti-inflammatory drugs. Trends in Pharmacological Sciences. 2007;28(10):501-5.

Walter A, Schäfer M, Cecconi V, Matter C, Urosevic-Maiwald M, Belloni B, Schönewolf N, Dummer R, Bloch W, Werner S, Beer HD, Knuth A, van den Broek M. Aldara activates TLR7-independent immune defence. Nat Commun. 2013;(4):1560.

Wang R. Physiological implications of hydrogen sulfide: a whiff exploration that blossomed. Physiol Rev. 2012;92(2):791-896.

Wang R. Two's company, three's a crowd: can H2S be the third endogenous gaseous transmitter? FASEB J. 2002;16(13):1792-8.

Warshaw TG, Herrmann F. Studies of skin reaction to propylene glycol. J Invest Dermatol. 1952;19(6):423-30. 
Watanabe M, Osada J, Aratani Y, Kluckman K, Reddick R, Malinow MR, Maeda N.Mice deficient in cystathionine beta-synthase: animal models for mild and severe homocysteinemia. Proc Natl Acad Sci U S A. 1995;92(5):1585-9.

Whiteman M, Li L, Rose P, Tan CH, Parkinson DB, Moore PK. The effect of hydrogen sulfide donors on lipopolysaccharide-induced formation of inflammatory mediators in macrophages. Antioxid Redox Signal. 2010;12(10):1147-54.

Williams JD, Tate BJ. Occupational allergic contact dermatitis from olive oil. Contact Dermatitis. 2006;55:251-2.

Williams SC. New biologic drugs get under the skin of psoriasis. Nature Medicine. 2012;4:18(5):638.

Wohn C, Ober-Blöbaum JL, Haak S, Pantelyushin S, Cheong C, Zahner SP, Onderwater S, Kant M, Weighardt H, Holzmann B, Reizis B, Becher B, Prens EP, Clausen BE. Langerin(neg) conventional dendritic cells produce IL-23 to drive psoriatic plaque formation in mice. Proc Natl Acad Sci U S A. 2013;110(26):10723-8.

Yanaba K, Kamata M, Ishiura N, Shibata S, Asano Y, Tada Y, Sugaya M, Kadono T, Tedder TF, Sato $\mathrm{S}$. Regulatory B cells suppress imiquimod-induced, psoriasis-like skin inflammation. J. Leukoc. Biol. 2013;(94):563-57.

Yang G, Wu L, Jiang B, Yang W, Qi J, Cao K, Meng Q, Mustafa AK, Mu W, Zhang S, Snyder SH, Wang R. H2S as a physiologic vasorelaxant: hypertension in mice with deletion of cystathionine gamma-lyase. Science. 2008;322(5901):587-90.

Yosipovitch G, Bernhard JD. Chronic Pruritus. N Engl J Med. 2013;368:1625-34.

Yosipovitch G, Goon A, Wee J, Chan YH, Goh CL.The prevalence and clinical characteristics of pruritus among patients with extensive psoriasis. British Journal of Dermatology. 2000;(143):969-73.

Zanardo RC, Brancaleone V, Distrutti E, Fiorucci S, Cirino G, Wallace JL. Hydrogen sulfide is an endogenous modulator of leukocyte-mediated inflammation. FASEB J. 2006;20(12):2118-20.

Zhang Q, Putheti P, Zhou Q, Liu Q, Gao W. Structures and biological functions of IL-31 and IL-31 receptors. Cytokine Growth Factor Rev. 2008;19(5-6):347-56.

Zhao Y, Biggs TD, Xian M. Hydrogen sulfide (H2S) releasing agents: chemistry and biological applications. Chem. Commun. 2014;(50):11788-805. 